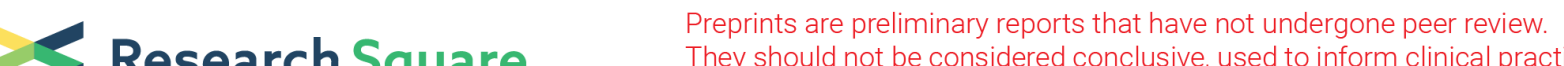 $\begin{array}{ll}\text { Research Square } & \begin{array}{l}\text { They should not be considered conclusive, used to inform clinical practice, } \\ \text { or referenced by the media as validated information. }\end{array}\end{array}$
}

\section{Alveolar Neutrophilic Recruitment in COVID-19 May Not be Mediated by Th17 Response}

Marina L V Azevedo ( $\square$ maluviolazevedo@gmail.com )

Pontifical Catholic University of Parana https://orcid.org/0000-0002-0559-5459

Caroline Busatta Vaz de Paula

Pontifical Catholic University of Parana

\section{Seigo Nagashima}

Pontifical Catholic University of Parana

Cleber Machado de Souza

Research Institute Pele Pequeno Principe

Anna Flavia Miggiolaro Ribeiro

Pontifical Catholic University of Parana

Jarbas Silva Motta Junior

Pontifical Catholic University of Parana

Mineia Alessandra Scaranello Malaquias

Pontifical Catholic University of Parana

Sonia Mara Raboni

Federal University of Parana

Plinio Cezar Neto

Pontifical Catholic University of Parana

Daiane Gavlik de Souza

Federal University of Parana

Cristina Pellegrino Baena

Pontifical Catholic University of Parana

Lucia de Noronha

Pontifical Catholic University of Parana

\section{Research Article}

Keywords: SARS-CoV-2, Influenza A Virus H1N1 Subtype, Interleukin-8, Interleukin-17A, neutrophils, immunohistochemistry

Posted Date: July 22nd, 2020

DOl: https://doi.org/10.21203/rs.3.rs-36238/v2 
License: (c) (i) This work is licensed under a Creative Commons Attribution 4.0 International License. Read Full License 


\section{Abstract}

Introduction: The COVID-19 current pandemic disease differs from the H1N1pdm09 caused by Influenza A virus $\mathrm{H} 1 \mathrm{~N} 1$ subtype, by how it induces a pro-inflammatory response in infected lungs.

Objective: Investigate the role of Th17 response in the pathogenesis of COVID-19 injury by analyzing the tissue expression of interleukins 8 and 17A and the neutrophils in lung samples of patients who die of COVID-19, comparing to H1N1pdm09. Study design and post-mortem results: Six lung samples from patients SARS-CoV-2 infected (COVID-19 group), and ten lung samples from adults who died from H1N1pdm09 (H1N1 group), were tested. A control group was also added to the study. H\&E slides were used for neutrophils scoring. The tissue expression of IL-8 and IL-17A was identified by immunohistochemistry. Tissue expression increasing of IL-17A and IL-8 and a higher number of neutrophils were identified in samples from the H1N1 group when compared to the COVID-19 group.

Discussion: It is suggested that the SARS-CoV-2 virus evokes an exacerbated response of the host's immune system but differs from that observed in the H1N1pdm09 disease because it may not be trigger by Th17 response. With the low expression of IL-8, IL-17A, neutrophil recruitment to the site of infection becomes impaired, resulting in viral persistence. On the other hand, in the COVID-19 disease, the immune response by Th2 cells seems to be exacerbated, observed by the extent of the lung injury. This uncontrolled response and, mainly, the lack of a therapeutic target, culminates in disease progression and, consequently, in shorter survival time.

\section{Introduction}

At the end of 2019, a new strain of the respiratory coronavirus (SARS-CoV-2) emerged from China and has spread rapidly around the world, causing a wave of infections and deaths. Until May 24 of this year, the virus has infected more than $5,200,000$ people, with over 337,600 deaths worldwide[1].

With the rapid worsening of symptoms in infected patients, clinicians have confronted a great challenge, since there are still no specific therapies[2]. Without a specific antiviral agent to treat those infected patients, numerous clinical trials are, in course, worldwide[3], such as antiviral and immunomodulatory activity drugs[4,5].

SARS-CoV-2 infection, called COVID-19 disease, evolves an acute respiratory distress syndrome (ARDS) with diffuse alveolar damage (DAD). The injury pattern of the infection seems to be a consequence of a complement system activation described as cytokine storm[6]. This process is mediated by the angiotensin-converting enzyme 2 (ACE-2) in lung tissue[7,8], but how this damage starts and compromises the lung tissue needs to be better investigated.

DAD is characterized by the development of intra-alveolar pulmonary edema and hyaline membrane. This is due to the increased permeability of the alveolar-capillary membrane triggered by SARS-CoV-2 pneumocytes infection[9], culminating in acute respiratory failure and the need for mechanical 
ventilation. This process is associated with a host defense response regulated by a complex interaction of cytokines and inflammatory cells closely related to the activation of tissue macrophages that release cytokines such as TNF-a, IL-1, and IL-6 that can recruit circulating neutrophils, amplifying the response[10,11,12,13].

The pulmonary inflammatory reaction to infectious agents, in general, begins with a Th1/Th17 response, producing IL-17 and stimulating pro-inflammatory cytokines (such as IL-8), with consequence increasing vascular permeability allowing the intense neutrophilic infiltrates[12,13].

This study aims to investigate the role of Th17 response in the pathogenesis of COVID-19 lung injury by analyzing the relationship between neutrophil recruitment and DAD in patients who died from COVID-19 and compare to patients who died of H1N1pdm09 (the pandemic disease caused by the Influenza A virus H1N1 subtype).

\section{Study Design And Post-mortem Results \\ 2.1 Post-mortem samples and methods}

This present study was approved by the National Research Ethics Committee (Conselho Nacional de Ética em Pesquisa - CONEP) by the numbers 3.944.734/2020 and 2.550.445/2018 and families consented to the post-mortem biopsy.

The COVID-19 group comprises post-mortem lung samples of patients whose cause of death was DAD caused by SARS-CoV-2 ( $n=6$, positive nasal swab RT-PCR for SARS-CoV- 2 in more than one sample). Clinical data of 6 cases were obtained from medical records during hospitalization in the ICU at Hospital Marcelino Champagnat in Curitiba-Brazil.

The H1N1 group comprises necropsies lung samples of patients whose cause of death was DAD caused by $\mathrm{H} 1 \mathrm{Npdm09}(\mathrm{n}=10$, pandemic Influenza A virus H1N1 subtype positive RT-PCR in fresh lung samples) during the 2009 pandemic.

The CONTROL group $(n=11)$ was composed of lung samples from patients who died of cardiovascular and neoplastic disease, not involving lung lesions.

The sample size was not determined statistically. The number of samples that comprised each group was determined by the number of patients who died due to the disease, in the period of time in which the research was carried out, and also according to those whose families accepted the use of a biopsy sample for study.

Survival was defined as the period between diagnosis and death.

The immunohistochemistry technique was used to analyzed IL-8 and IL-17A tissue expression. Monoclonal antibodies anti-IL-17A (rabbit polyclonal antibody, Abcam, Cambridge, UK, Cat\# ab91649, 
RRID: AB_10712684,1:200 dilution) and anti-IL-8 (rabbit polyclonal antibody, Abcam, Cambridge, UK, Cat\# ab7747, RRID: AB_306040, 1:200 dilution) were used as the primary antibodies. The validation of the antibodies, as well as the optimal dilution, was performed according to the manufacturer's instructions, using the recommended positive control, in these cases, human samples. The secondary polymer was Reveal Polyvalent HRP-DAB Detection System, Cat\# SPD-125, Spring Bioscience, CA, USA. The result is confirmed by the positivity of a positive control, that is, a sample known to be positive for a specific antibody that is allocated together with the patient's samples.

The immunostained slides were scanned (Axion Scan.Z1 Scanner, Zeiss AG, Oberkochen, Germany), and then ZEN Blue Edition (Zeiss, Germany) were used to ramdomly generate ten high-power fields per case $(\mathrm{HPF}=40 \mathrm{x}$ objective). The image analysis was performed (Image-Pro Plus 4 software). After that, a percentage of IL-8 and IL-17A tissue expression per HPF was obtained in each case.

H\&E slides high-resolution images were used to perform the neutrophil scoring in $30 \mathrm{HPF}$. The scoring was made in hot spot areas, only in the septum or alveolar lumen.

The comparison of two groups, concerning quantitative variables, was performed using the nonparametric Kruskal-Wallis test. Values of $p<0.05$ indicated statistical significance. The data were analyzed using the IBM SPSS Statistics v.20.0 software. Armonk, NY: IBM Corp.

\subsection{Histopathological and immunohistochemistry results}

Clinical characteristics of the COVID-19 $(n=6), \mathrm{H} 1 \mathrm{~N} 1(n=10)$, and CONTROL groups as age, gender, pathological patterns, survival, IL-17A and IL-8 tissue expression, and the neutrophils score are listed in Table 1.

Table 1. Comparative table between COVID-19, H1N1, and CONTROL groups for gender, age, survival in days, mechanical ventilation in days, IL-8 tissue expression, IL-17A tissue expression, and neutrophil score. 


\begin{tabular}{|c|c|c|c|c|}
\hline Data & Variable & $\begin{array}{l}\text { COVID-19 } \\
(n=6)\end{array}$ & $\begin{array}{l}\text { H1N1 } \\
(n=10)\end{array}$ & $\begin{array}{l}\text { CONTROL } \\
(n=11)\end{array}$ \\
\hline \multirow[t]{2}{*}{ Gender } & Male & $66.6 \%$ & $80.0 \%$ & $62,5 \%$ \\
\hline & Female & $33.3 \%$ & $20.0 \%$ & $37,5 \%$ \\
\hline $\begin{array}{l}\text { Age } \\
\text { (years) }^{1}\end{array}$ & - & 76.5/80.5 (53-87) & $43.5 / 44(23-61)$ & $42.3 / 45(18-60)$ \\
\hline $\begin{array}{l}\text { Survival } \\
\text { (days) }^{1}\end{array}$ & -- & $12.8 / 10(2-32)$ & $4.70 / 1.5(1-19)$ & - \\
\hline $\begin{array}{l}\text { mechanical } \\
\text { ventilation }\end{array}$ & & $9.7 / 8(0-21)$ & $4.70 / 1.5(1-19)$ & - \\
\hline $\begin{array}{l}\text { Histological } \\
\text { pattern DAD }\end{array}$ & & $\begin{array}{l}\text { Interstitial pneumonitis } \\
\text { with scarce septal } \\
\text { neutrophils with hyaline } \\
\text { membrane and micro } \\
\text { thrombosis }\end{array}$ & $\begin{array}{l}\text { Interstitial pneumonitis } \\
\text { with high septal } \\
\text { neutrophils infiltration } \\
\text { and no micro } \\
\text { thrombosis }\end{array}$ & Normal septum \\
\hline \multirow{2}{*}{$\begin{array}{l}\text { IL-8 tissue } \\
\text { expression } \\
\text { per HPF } F^{1,2}\end{array}$} & - & $0.79 / 0.19(0.004-3.62)$ & $4.15 / 4.13(0.72-9.13)$ & $\begin{array}{l}0.00 / 0.00001(0- \\
0.0001)\end{array}$ \\
\hline & & $0.0092^{*}$ & & $0.0008 * *$ \\
\hline \multirow{2}{*}{$\begin{array}{l}\text { IL-17A } \\
\text { tissue } \\
\text { expression } \\
\text { per HPF }{ }^{1,2}\end{array}$} & - & $3.86 / 1.50(0.55-14.63)$ & $9.91 / 9.73(4.34-15.44)$ & $\begin{array}{l}0.00 / 0.00(0- \\
0.003)\end{array}$ \\
\hline & & $0.017 *$ & & $0.0007 * *$ \\
\hline \multirow[t]{2}{*}{$\begin{array}{l}\text { Number of } \\
\text { neutrophils } \\
\text { per HPF } \text { I }^{1,3}\end{array}$} & - & 4.88/4.7 (1.50-8.80) & 17.6/16.7 (11.4-25.8) & $\begin{array}{l}3.8 / 3.2(1.8- \\
10.5)\end{array}$ \\
\hline & & $0.0011 *$ & & $0.1746 * \star$ \\
\hline
\end{tabular}

Legend: ${ }^{1}$-Average/Median (Min-Max); ${ }^{2}$ - mean tissue expression percentage in 10 high power field (HPF). 3 - mean number in 30HPF. DAD: diffuse alveolar damage. ${ }^{*}=p$-values obtained were compared between COVID-19 versus H1N1. ** $=p$-values obtained were compared between COVID-19 and CONTROL group. $p$-values were performed using the non-parametric Kruskal-Wallis test.

The main histopathological and immunohistochemical results of COVID-19 and H1N1 groups are shown in Figure 1. Regarding the neutrophils score, the H1N1 group presented statistically higher percentages when compared to the COVID-19 group $(p=0.0011)$. The IL-8 and IL-17A tissue expression of the COVID- 
19 compared with the H1N1 group are also shown in Figure 1. IL-17A and IL-8 had significantly higher tissue expression in the H1N1 group compared to COVID-19 ( $p=0.017$ and 0.0092, respectively).

The lung histopathological features of the COVID-19 group presented proliferative DAD, with type 2 pneumocyte hyperplasia, hyaline membranes with mild septal thickness, focal mild alveolar edema, scarce septal lymphocytic infiltration, and also poor septal and intra-alveolar neutrophils recruitment. We observed a variable number of small fibrinous thrombi in small and medium pulmonary arteries following by neutrophilic endotheliitis in all cases. Endothelial tumefaction in the alveolar-capillaries is another indicator of endothelial activation. Pulmonary infarctions were not observed. Signs of secondary bacterial pneumonia were not observed.

The histopathological features of $\mathrm{H} 1 \mathrm{~N} 1 \mathrm{pdm} 09$ interstitial pneumonitis are different than observed in COVID-19 cases. There are fewer hyaline membranes but higher septal thickness with massive setal lymphocytic infiltration, and also, septal and intra-alveolar neutrophils recruitment. There is no significant endothelial activation, fibrinous, and neutrophilic endotheliitis. Signs of bacterial co-infections were found in $80 \%$ of cases, with the presence of Haemophilus influezae (60\%), Streptococcus pneumoniae (10\%), and Mycoplasma pneumoniae (10\%) being found in the post-mortem lung fresh samples by PCR reactions with respective positive blood culture.

The data that support the findings of this study are available from the corresponding author upon reasonable request.

\section{Discussion}

IL-17A/IL-8 tissue expression and neutrophils score were analyzed to evaluate the Th17 response promoting antiviral activity, neutrophil-mediated lung injury, and, consequently, DAD. In response to a viral infection, both IL-8 and IL-17A are secreted by macrophages and T lymphocytes to recruit mainly neutrophils[14]. Other studies corroborated these data in Th17-mediated response with a serological increase of IL-17 in patients with the H1N1pdm09[15,16]. H1N1 group features corroborate these findings, as an increase of the IL-8 and IL-17A lung tissue expression and the neutrophils score were observed. Although the presence of neutrophils is vital to the defense process, their excessive activation can generate severe tissue damage. This pattern was not observed in the COVID-19 group, where IL-17A and IL-8 tissue expression and neutrophil score were lower than the H1N1 group (but also higher than the CONTROL group), indicating that there may be a reduction of Th17 response during the evolution of COVID-19.

A recent study described that, although out of the expected patterns of viral lung infection, patients with COVID-19 showed an increased Th2 response. The innate and Th1 responses, mediated by macrophages, neutrophils, and $\mathrm{T}$ lymphocytes, are known to be more effective in controlling the viral infection, but for reasons that are still unclear, this process seems to be inhibited in SARS-CoV-2 infection[17]. The innate and adaptive Th1 response modulation occurs due to the presence of viral proteins and the consequent activation of TCD8+ lymphocytes, which are remarkably reduced in infection by SARS-CoV-2. Another 
current work dedicated to SARS-CoV-2, reported the possible evasion of the immune system by the virus, explained by the increased incubation time, in comparison with viruses such as Influenza[17,18,19].

Under normal conditions, after circulation for 6-12 hours, neutrophils undergo apoptosis, but in the inflammatory state, apoptosis is inhibited, and the presence of IL-8 seems responsible for this process[14]. Disturbances in the innate response mechanism observed in recent studies of SARS-CoV-2 infection may explain the low expression of IL-8, responsible, among others, for the chemoattraction of neutrophils to the injury site[20,21].

Recent studies demonstrate that Influenza A variants can trigger the more severe neutrophilic response that appears to be determinant of the severity of lung injury and the tragic outcomes. It also has shown that these cytokines and neutrophils chemoattraction may be associated with the pathogenesis of respiratory diseases by exacerbating the inflammatory response[17,22]. In our study, the COVID-19 lower tissue expression of IL-17A and IL-8 accompanied by lower neutrophil score may demonstrate that the SARS-CoV-2 inflammatory response's pathogenesis differs from that observed in the H1N1pdm09 disease[23]. One study described neutrophils with possible antiviral potential, and neutrophil depletion observed in SARS-CoV-2 may be associated with the virus immune evasion capacity[24,25].

Five out of the six patients in the COVID-19 group have received mechanical ventilation, and all ten patients in the H1N1 group underwent this same intensive care procedure. We can also observe that the average time of mechanical ventilation in the COVID-19 group was higher than H1N1 group, however, when the range of mechanical ventilation of both groups is compared, we see that they are very close (021 and 1-19 days for COVID-19 and H1N1 groups, respectively). Besides, we can also see that both IL17A/IL-8 tissue expression and the neutrophils score remain low in almost all COVID-19 group patients regardless of survival time, which is a very close mechanical ventilation time of almost all patients. Furthermore, COVID-19, unlike H1N1pdm09 patients, underwent gentle mechanical ventilation to avoid angering the alveolar injury by barotrauma with a consequent increase of cytokine release. With these observations, we may assume that, in this study, perhaps the gentle mechanical ventilation may not aggravate the DAD in COVID-19. However, we must take into account that data from post-mortem samples reflect only the time of death and fail to predict the evolution of the disease[26].

Our study has some limitations, and the small sample is the major one since we studied only six patients. Another one is that this autopsy data also represent static information at the time of death, and they cannot reconstruct the disease evolution. We also compare the inflammation process caused by two different virus families, such as the pandemic Influenza A virus H1N1 subtype, and SARS-CoV-2 [26].

Innumerable therapies have been proposed to prevent the evolution of SARS-CoV-2 infection and consequent lung damage. The use of off-label drugs occurs as immediate alternatives in pandemic cases[2]. In this context, remdesivir, a promising antiviral against RNA virus, has been proposed as an emergency therapy without definitive results. According to the data obtained in this study, a monoclonal antibody that binds IL-17A (secukinumab) or IL-17RA (brodalimab) may not be a useful alternative, since Th17 does not seem to be the main pathway of lung injury induced by SARS-CoV-2. 
Our findings showed that $80 \%$ of the $\mathrm{H} 1 \mathrm{~N} 1$ group tested for the presence of bacteria in fresh lung samples by PCR had positive results. These bacterial types are commonly found in infectious processes and may be secondary after viral infection. However, we did not find bacterial co-infections in the COVID19 group lung samples, and the blood culture of these patients was negative. Some authors have reported that IL-17A deficiency might protect from bacterial lung infection because some type of bacteria might drive IL-17A functions during pulmonary infection. Furthermore, reducing the release of IL-17A might be a therapeutic option in some bacterial pneumonia, a common co-infection in viral lung injury[27].

Based on this information, SARS-CoV-2 appeared to promote injury by different mechanisms, evading an adaptive Th1 response and inducing a Th2 response, ineffective against viral agents. In contrast, H1N1pmd09 demonstrated an intense innate response Th1/Th17, responsible for severe lung injury mediated by increased neutrophils recruitment. In both cases, the induction of an exacerbated immune response, either via Th1 or Th2, can result in a worsening of the clinical condition and survival time. Lastly, the search for efficient therapies that decrease viral replication or block the inflammatory response seems to be the key to restabilizing infected patients.

\section{Declarations}

Conflict of Interest

The authors declare that they have no conflict of interests.

Author Contributions

MLVA performed the immunohistochemistry, was responsible for the analysis and interpretation of data and drafted the manuscript. CBVP is a Ph.D. student in our group and supported all experiments, including the immunohistochemistry reactions of the SARS-CoV-2 group, and article writing. SN is an MSc. Student of our group and support in image acquisition and preparation and also article writing. CMS assisted with statistical analysis data, contributed to the writing of the manuscript, and the results tables and MASM analyzed the data and contributed to the writing of the manuscript. SMR was responsible for collecting and preparing H1N1pmd09 patients' samples and PCR to confirm the virus presence. AFMR and JSMJ were responsible for the collection and preparation of SARS-CoV-2 patients' samples and provided the medical records with the data needed for analysis. PCN and DGS are graduate students and provided operational support. CPB and LN supervised the project and were a significant contributor to the manuscript review and editing. All authors read and approved the final manuscript.

\section{Funding}

This work was supported by productivity research level 2 of the National Council for Scientific and Technological Development (CNPq). 
The authors express their gratitude to Dra. Márcia Olandoski for performing the statistical analysis.

\section{References}

1 Coronavirus disease 2019 (COVID-19) Situation Report - 118. 2020.

2 Kalil AC. Treating COVID-19-Off-Label Drug Use, Compassionate Use, and Randomized Clinical Trials During Pandemics. JAMA. 2020.

3 Baden LR, Rubin EJ. Covid-19 - The Search for Effective Therapy. N Engl J Med. 2020 7; 382(19): 1851-1852.

4 Wang M, Cao R, Zhang L, Yang X, Liu J, Xu M, Shi Z, Hu Z, Zhong W, Xiao G. Remdesivir and chloroquine effectively inhibit the recently emerged novel coronavirus (2019-nCoV) in vitro. Cell Res. 2020; 30(3): 269-271.

5 Gautret P, Lagier JC, Parola P, Hoang VT, Meddeb L, Mailhe M, Doudier B, Courjon J, Giordanengo V, Vieira VE, Dupont HT, Honoré S, Colson P, Chabrière E, La Scola B, Rolain JM, Brouqui P, Raoult D. Hydroxychloroquine and azithromycin as a treatment of COVID-19: results of an open-label nonrandomized clinical trial. Int J Antimicrob Agents. 2020; 20: 105949.

6 Mehta P, McAuley DF, Brown M, et al. COVID-19: consider cytokine storm syndromes and immunosuppression. Lancet (London, England) 2020; 0(0).

7 McGonagle D, Sharif K, O'Regan A, Bridgewood C. The Role of Cytokines, including Interleukin-6 in COVID-19 induced Pneumonia and Macrophage Activation Syndrome-Like Disease. Autoimmun Ver. $2020 ; 102537$.

8 Li W, Moore MJ, Vasllieva N, et al. Angiotensin-converting enzyme 2 is a functional receptor for the SARS coronavirus. Nature. 2003; 426(6965): 450-4.

9 Costa DC, Rocha E, Ribeiro TF. Association of alveolar recruitment maneuvers and prone position in acute respiratory disease syndrome patients. Rev Bras Ter Intensiva. 2009; 21(2): 197-203.

10 Barbas CSV. Acute lung injury and acute respiratory distress syndrome: diagnostic hurdles. J Bras Pneumol. 2007; 33(4): xxv-xxvi;

11 Meduri GU. Host Defense Response and Outcome in ARDS. 1997; Chest, 112(5), 1154-1158.

12 Wu D, Yang XO. TH17 responses in cytokine storm of COVID-19: An emerging target of JAK2 inhibitor Fedratinib. J Microbiol Immunol Infect. 2020; pii: S1684-1182(20) 30065-7.

13 Chatzopoulou F, Gioula G, Kioumis I, Chatzidimitriou D, Exindari M. Identification of complementrelated host genetic risk factors associated with Influenza A (H1N1) pdm09 outcome: challenges ahead. 
Med Microbiol Immunol. 2019; 208(5): 631-640

14 Kobayashi Y. The role of chemokines in neutrophil biology. Front Biosci. 2008; 13: 2400-2407

15 Song X, He X, Li X, Qian Y. The roles and functional mechanisms of interleukin-17 family cytokines in mucosal immunity. Cell Mol Immunol. 2016;13(4):418-31.

16 Vidy A, Maisonnasse P, Da Costa B, Delmas B, Chevalier C, Le Goffic R. The Influenza Virus Protein PB1 F2 Increases Viral Pathogenesis through Neutrophil Recruitment and NK Cells Inhibition. PLoS One. 2016; 11(10): e0165361.

17 Roncati L, Nasillo V, Lusenti B, Riva G. Signals of Th2 immune response from COVID-19 patients requiring intensive care. Ann Hematol. 2020; s00277-020-04066-7.

18 Liu Y, Yang Y, Zhang C, Huang F, Wang F, Yuan J, Wang Z, Li J, Feng C, Zhang Z, Wang L, Peng L, Chen L, Qin Y, Zhao D, Tan S, Yin L, Xu J, Zhou C, Jiang C, Liu L. Clinical and biochemical indexes from 2019-nCoV infected patients linked to viral loads and lung injury. Sci China Life Sci. 2020; 63(3): 364-374.

19 Prompetchara E, Ketloy C, Palaga T. Immune responses in COVID-19 and potential vaccines: Lessons learned from SARS and MERS epidemic. Asian Pac J Allergy Immunol. 2020; 38(1): 1-9.

20 Hannoodee S, Nasuruddin DN. Acute Inflammatory Response. Treasure Island: StatPearls Publishing; 2020.

21 Azkur AK, Akdis M, Azkur D, Sokolowska M, Veen WV, Brüggen MC, O'Mahony L, Gao Y, Nadeau K, Akdis CA. Immune response to SARS-CoV-2 and mechanisms of immunopathological changes in COVID19. J Allergy Clin Immunol 2020; 10.1111/all.14364

22 Kramer JM, Yi L, Shen F, Maitra A, Jiao X, Jin T, et al. Cutting edge: evidence for ligand-independent multimerization of the IL-17 receptor. J Immunol. 2007.

23 Wong CK, Cao J, Yin YB, Lam CWK. Interleukin-17A activation on bronchial epithelium and basophils: A novel inflammatory mechanism. Eur Respir J. 2010; 35(4): 883-93.

24 Naumenko V, Turk M, Jenne CN, Kim SJ. Neutrophils in viral infection. Cell Tissue Res. 2018; 371(3): 505-516.

25 Kikkert M. Innate Immune Evasion by Human Respiratory RNA Viruses. J Innate Immun. 2020; 12 :420.

26 Ackermann M, Verleden SE, Kuehnel M, Haverich A, Welte T, Laenger F, Vanstapel A, Werlein C, Stark H, Tzankov A, Li WW, Li WV, Mentzer SJ, Jonigk D. Pulmonary Vascular Endothelialitis, Thrombosis, and Angiogenesis in Covid-19. NEJM. 2020; doi: 10.1056/NEJMoa2015432 
27 Wonnenberg, B., Jungnickel, C., Honecker, A., Wolf, L., Voss, M., Bischoff, M., Tschernig, T., Herr, C., Bals, R., Beisswenger, C. IL-17A attracts inflammatory cells in murine lung infection with P. aeruginosa. Innate Immun. 2016; 22(8):620-25.

\section{Figures}

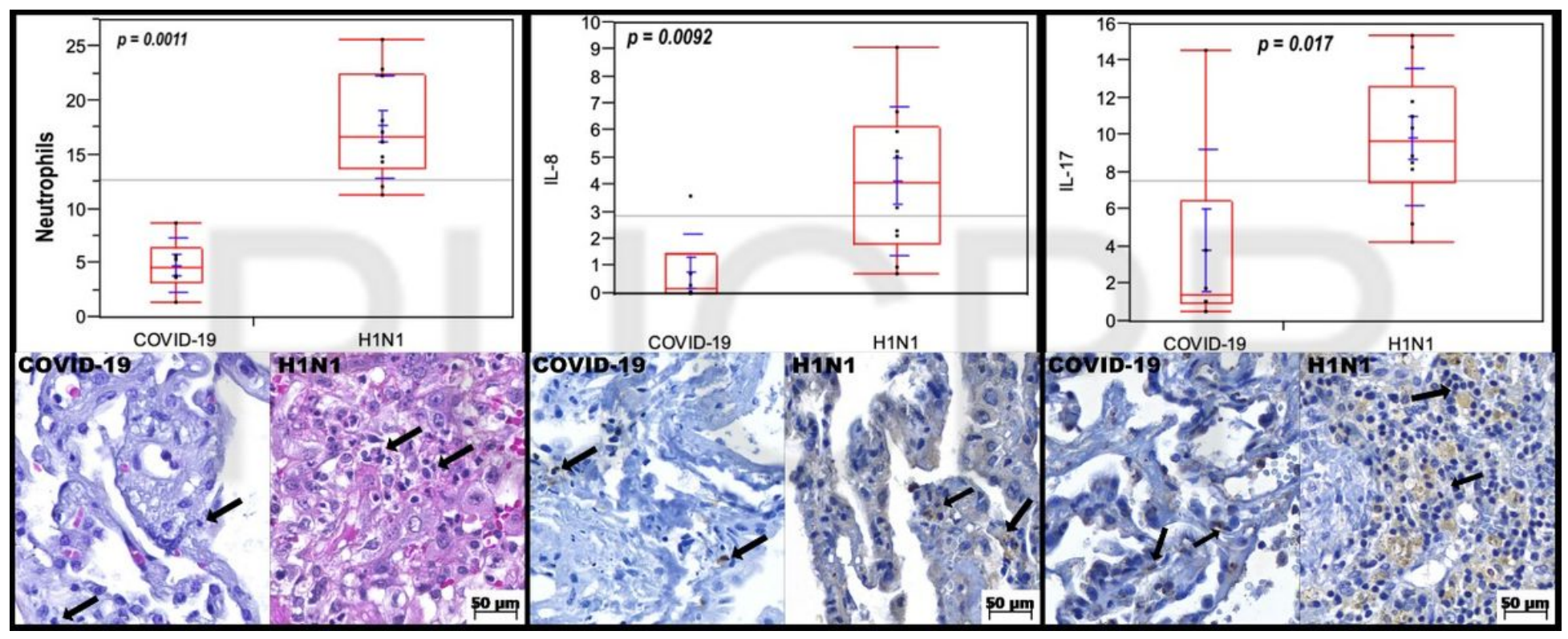

\section{Figure 1}

The comparative graphic between COVID-19 and H1N1 groups for the neutrophil score. H\&E stain on lung tissue neutrophilic infiltration. The COVID-19 and H1N1 with the black arrows pointing neutrophils. Comparative graphs between the COVID-19 and H1N1 groups regarding IL-8 and IL-17A tissue expression. Black arrows show septal lymphocytes expressing IL-8 and IL-17A in both groups, scarce in the COVID-19 group, and numerous in the H1N1 group. In H1N1, it observed numerous lymphocytes expressing IL-17A intermixed with numerous neutrophils.

\section{Supplementary Files}

This is a list of supplementary files associated with this preprint. Click to download.

- Suppl.jpg 